\title{
cover feature:
}

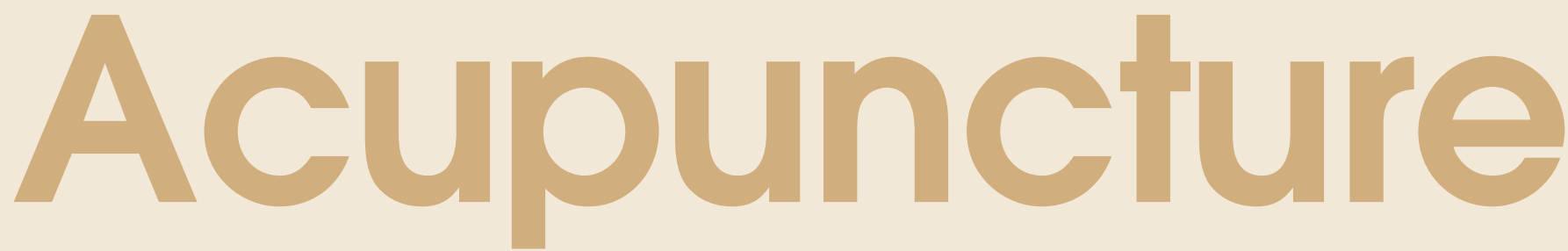

\section{takes the pain out of dentistry}

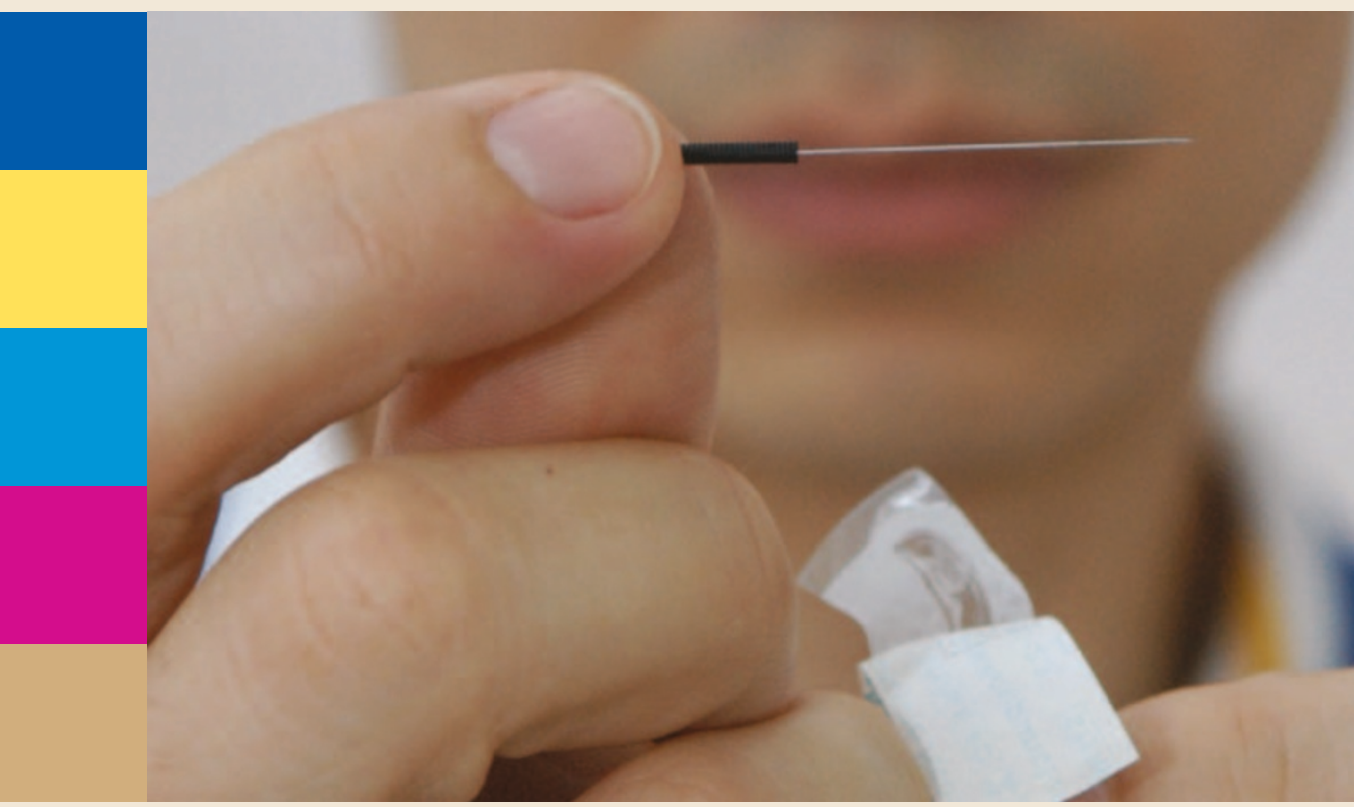

More and more dentists are combining the ancient Chinese therapy acupuncture with modern dentistry techniques to help patients cope with conditions from anxiety to pain relief. Julie Ferry takes a closer look.

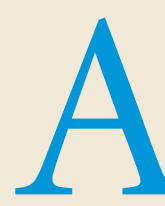
bout one in five people in the UK use a complementary medicine and one of the most popular therapies in this rapidly growing market is acupuncture. In recent years a growing number of dentists have been using this alternative therapy as an adjunct to conventional treatment.

Acupuncture has been used to treat a wide range of dental-related conditions including anxiety, nausea, gag reflex, facial pain, TMJ pain, dry mouth, sinusitis and migraine.

Peter Kosasih, a dentist at the One 4 One dental practice in Putney, south London, told Vital he has used the ancient therapy to treat his patients for the past eight years. He traced his long-time interest in acupuncture back to his Chinese roots.

"Initially, I wanted to learn more about using it as an anaesthetic but I couldn't find anyone in Britain who was doing that. In China people have had quite major operations using just acupuncture. So, I decided to do the normal acupuncture training, which was very comprehensive."

Peter, who is registered with the British

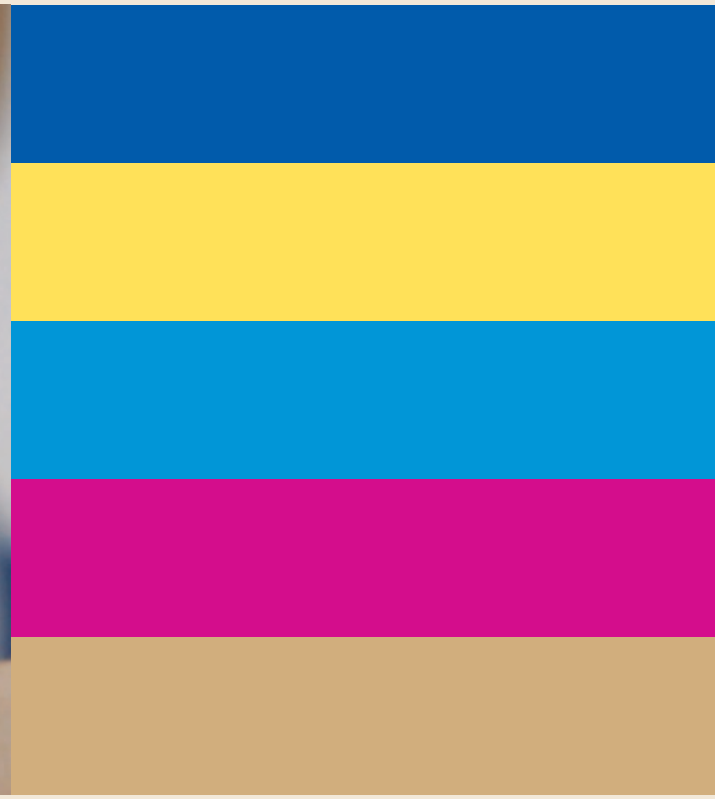

Medical Acupuncture Society (BMAS), said to qualify he did a series of acupuncture courses overseen by the Society, which took several years to complete.

"The results that I have had with patients have been quite remarkable especially with neck pain, sinusitis and gag reflex", said Peter who graduated in dentistry from Guys' and St Thomas' hospital in London in 1982.

The effect on patients has been very successful, said his dental nurse, Estela Nalden, adding that she was particularly surprised by the improvement in patients anxious about dental treatment.

"After patients have had acupuncture they are a lot calmer. I am not certain whether it is the acupuncture or the overall experience of spending time with the patient... but you can really see a difference", she said.

Estela said she had seen many anxious patients emerge from the clinic transformed after acupuncture.

"When I talk to them afterwards they say that they can't explain what they feel like but the fear has gone." 


\section{cover feature}

\section{${ }^{6}$ I was quite sceptical at first but I was really surprised at how well it worked..."}

possible to treat them in practice", said Sian who works at the Isebrook hospital in Wellingborough, Northamptonshire.

Dentists do not refer patients to have acupuncture but it is an additional service offered by the hospital department, said Sian.

"Some patients don't want acupuncture and others want to try it because they can't stand the pain or can't stand being so phobic and want to overcome it. Every patient is different", she said.

Sian has offered acupuncture for the past five years and said that even though she doesn't use it that often, it is a good skill to have. She admitted that she doubted the science behind the treatment but said she was more concerned with the results.

"Sometimes I think the success of acupuncture may be a psychological thing... But who cares? If it works and they can accept the treatment that they need when they couldn't before, it has got to be a good thing."

Sian's colleague dental nurse Litta Laczynski was another advocate who experienced first hand the benefits of acupuncture.

Litta said she has hayfever and last year was struggling with a bad episode when Sian suggested she try acupuncture.

"It stopped my eyes from watering and dried up my nose within an hour. I was quite sceptical at first but I was really surprised at how well it worked and I am definitely having it done again this year."

Litta's experience developed her interest in the therapy and she said she empathised with patients having the treatment. It was particularly satisfying to see the treatment work on nervous patients who have had a bad experience at the dentist.

"We used it on a patient with a really bad

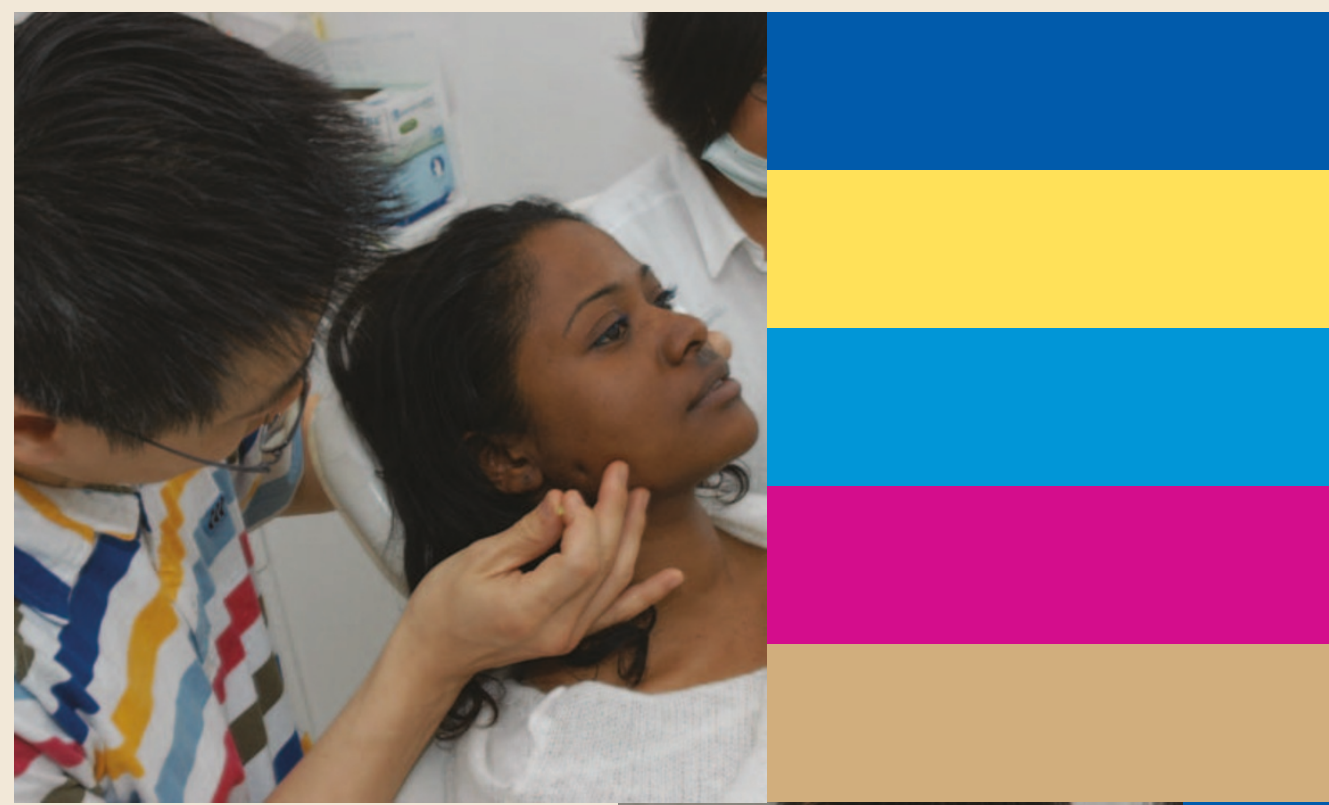

gagging reflex and we actually managed to get some treatment finished on him, which he hadn't been able to do for a long time. It was difficult but we succeeded."

Litta agreed with Estela's view that dental nurses did not have a large role to play during treatment, but the support they gave patients was vital to the treatment's success.

"My task is to reassure patients and to keep their trust, because if you lose their trust you've lost everything.

Altogether Litta said she was an advocate of acupuncture after her personal experience of the therapy.

"In my opinion it is wonderful, having had it done myself and being part of giving it to patients, I would recommend it."

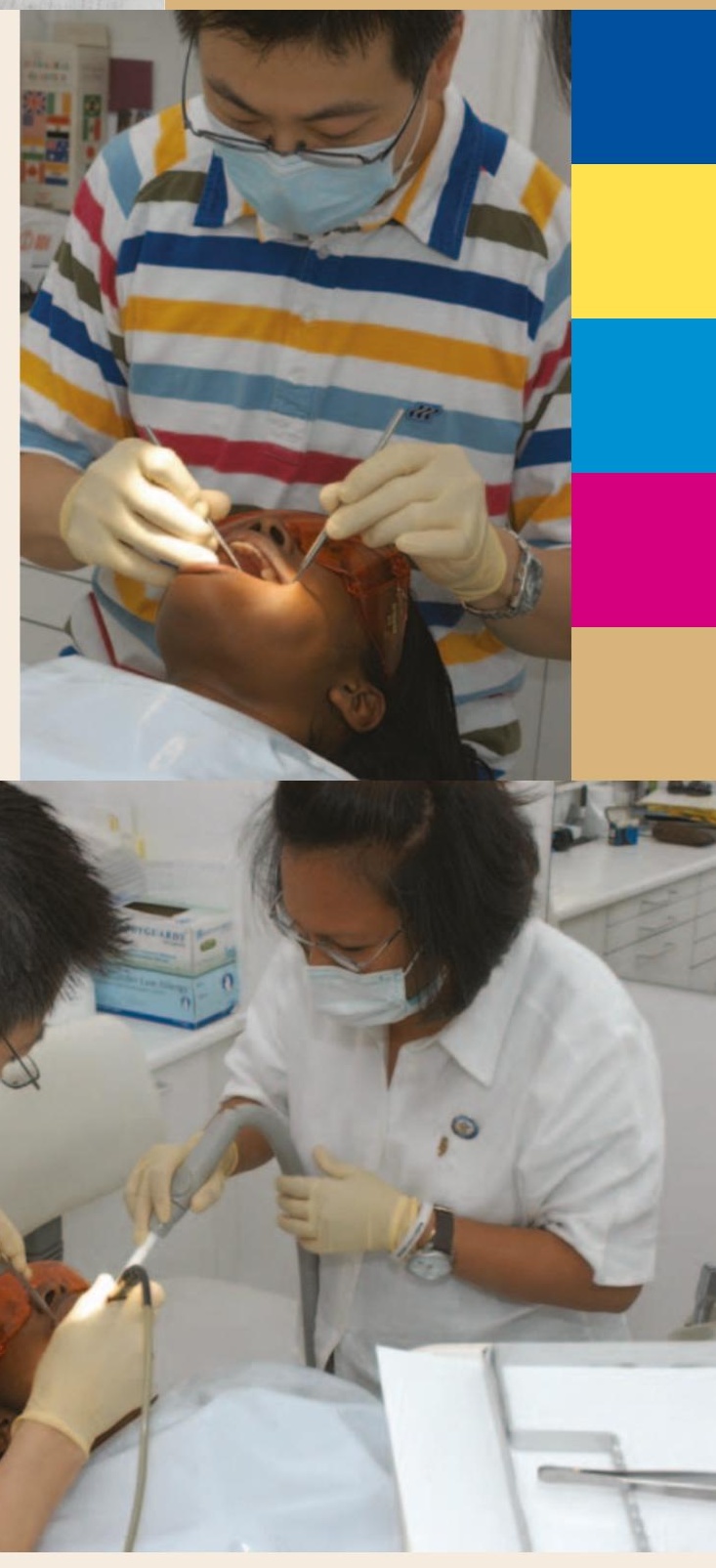

summer 0529 